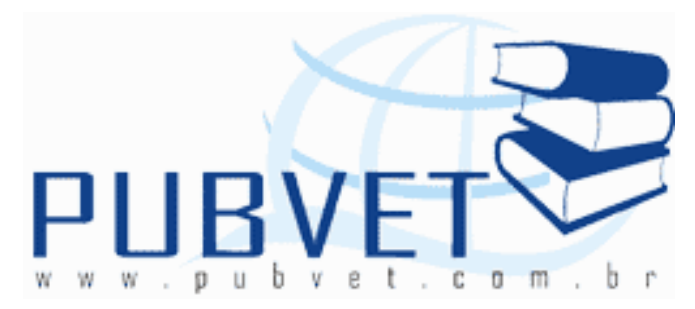

PUBVET, Publicações em Medicina Veterinária e Zootecnia.

\title{
Avaliação da qualidade de feno
}

Kíria Karolline Gomes Moreira ${ }^{1}$, Tiago Pereira Guimarães ${ }^{1}$, Barbara Juliana Martins Lemos ${ }^{1}$, Flávia Martins de Souza ${ }^{1}$, Sergio Fernandes Ferreira ${ }^{2}$, Verônica Auxiliadora Alves ${ }^{3}$

${ }^{1}$ Mestrando do curso de Pós Graduação em Ciência Animal da Universidade Federal de Goiás - Goiânia, Goiás; e-mail*: kiriakarolline@hotmail.com

2 Professor da Universidade Federal de Goiás - Departamento de Produção Animal - Goiânia, Goiás

${ }^{3}$ Doutorando do curso de Pós Graduação em Ciência Animal da Universidade Federal de Goiás - Goiânia, Goiás

\section{Resumo}

A produção de forragens conservadas de qualidade como o feno, é uma condição básica e crucial na produção animal, permitindo um manejo equilibrado, com suprimento de nutrientes de boa qualidade e com maior estabilidade durante todo o ano. A qualidade da forragem refere-se ao valor nutritivo da massa de forragem em interação com o consumo efetuado pelo animal e com o potencial de desempenho do animal, sendo que, um feno de boa qualidade deve apresentar características nutricionais que o diferencie dos demais. A utilização de plantas com alto valor nutritivo e com características adequadas para fenação é dos pontos principais na produção de feno de qualidade. Objetivou-se com este trabalho revisar e discutir tópicos que 
MOREIRA, K.K.G. et al. Avaliação da qualidade de feno. PUBVeT, Londrina, V. 7, N. 1, Ed. 224, Art. 1487, 2013.

abordem a avaliação da qualidade de fenos e sua influência no desempenho animal.

Palavras-chave: digestibilidade, fenação, qualidade do feno

\title{
Assessing the quality of hay
}

\begin{abstract}
The production quality of conserved forages such as hay, is a basic and crucial role in animal production, allowing a management balanced with nutrient supply of good quality and greater stability throughout the year. The forage quality refers to the nutritive value of forage mass in interaction with the consumption made by the animal and the animal's performance potential, with good quality hay should provide a nutritional characteristic that distinguishes it from others. The use of plants with high nutritional value and characteristics suitable for hay is of key points in the production of quality hay. Therefore, the aim of this work was to review and discuss topics that address the assessment of quality of hay and its influence on animal performance.
\end{abstract}

Keywords: digestibility, hay, quality

\section{INTRODUÇÃO}

O uso intensivo de pastagens torna a atividade pecuária mais econômica, pois não exige gastos com o manejo de arraçoamento dos animais. Entretanto, as exigências nutricionais dos animais são contínuas ao longo do ano e a oferta de forragem é irregular. A baixa disponibilidade de matéria seca e a redução na qualidade nutricional dos pastos durante a estação seca, são responsáveis pela perda de peso dos animais, pelo aumento da idade de abate e também pela menor rentabilidade do sistema produtivo. A fim de reduzir o efeito da estacionalidade tem-se adotado processos de conservação de forragens, de forma a garantir o fornecimento constante de alimentos aos 
MOREIRA, K.K.G. et al. Avaliação da qualidade de feno. PUBVeT, Londrina, V. 7, N. 1, Ed. 224, Art. 1487, 2013.

animais durante $o$ ano.

A produção de forragens conservadas de qualidade, através de processos como fenação ou ensilagem, é uma condição básica e crucial na produção animal, permitindo um manejo equilibrado, com suprimento de nutrientes de boa qualidade e com maior estabilidade durante todo o ano.

$O$ feno por possuir maior fibra efetiva em relação à silagem, permite maior participação do concentrado no balanceamento de rações, especialmente quando se pretende ganhos máximos de peso (SILVEIRA et al., 1999). MALLMANN et al. (2006) afirmam que a otimização do ambiente ruminal pode melhorar a utilização dos alimentos fibrosos, para isso, é necessário o fornecimento adequado de substratos que permitam a manutenção e o crescimento da microbiota ruminal.

Segundo REIS et al. (2001), a fenação é uma importante prática de manejo que permite maximizar a exploração das pastagens manejadas intensamente através da conservação do excesso de forragem produzida durante a estação de crescimento, sendo uma alternativa viável para se contornar o problema da escassez de forragem de boa qualidade durante a época de baixa produtividade.

A qualidade da forragem refere-se ao valor nutritivo da massa de forragem em interação com o consumo efetuado pelo animal e com o potencial de desempenho do animal. Forrageiras de baixa qualidade geralmente apresentam altos teores de fibra, baixos teores de proteína e baixa concentração de energia metabolizável, o que torna imprescindível a suplementação dos animais (REFFATTI, 2006). A correção das deficiências dos nutrientes proporciona níveis de produção aceitáveis, porém gera mais custos ao processo produtivo.

Algumas substâncias conhecidas como aditivos, auxiliam no processo de conservação de forragens e no controle de microrganismos como fungos, bactérias, mofos e bolores. Esses microrganismos geralmente provocam a redução do valor nutritivo da forragem consumindo os carboidratos solúveis disponíveis e aumentando os carboidratos estruturais. $O$ uso de aditivos no 
MOREIRA, K.K.G. et al. Avaliação da qualidade de feno. PUBVeT, Londrina, V. 7, N. 1, Ed. 224, Art. 1487, 2013.

tratamento de forragens de baixa qualidade eleva o valor nutritivo do alimento a ser fornecido, contribuindo em melhores resultados no desempenho animal (PÁDUA et al., 2011).

Um feno de boa qualidade deve apresentar características nutricionais que o diferencie dos demais, para isso, é necessário utilizar plantas com alto valor nutritivo e com características adequadas para fenação (JOBIM et al., 2001). Uma das principais características da planta adequada para fenação é a facilidade de desidratação. Alguns fatores intrínsecos como espessura, cutícula, diâmetro e comprimento do colmo, relação lâmina/caule também são importantes na escolha da forrageira. Fatores climáticos e de manejo (fertilidade do solo, pragas e doenças, armazenamento) correlacionam diretamente com a produção de um bom feno (JOBIM et al., 2007).

Existem várias formas de se avaliar a qualidade de um alimento conservado (olfato, análises químicas, bromatológicas, microbiológicas e desempenho dos animais). Analisar a composição químico-bromatológica antes e após a produção do feno é um importante passo para identificar possíveis perdas dos seus principais constituintes, porém, a avaliação da digestibilidade da forragem e o consumo animal são os fatores que melhor expressam seu valor nutritivo (JOBIM et al., 2007).

Os estudos da dinâmica digestiva em ruminantes têm permitido identificar fatores que afetam o consumo voluntário de forragens, tais como o grau de maturidade, relação caule-folha ou a forma de processamento. Esse conhecimento é considerado fundamental na formulação de programas eficientes de alimentação e para o desenvolvimento ou seleção de plantas forrageiras de maior qualidade nutritiva (LADEIRA et al., 2001).

Portanto, objetivou-se com este trabalho revisar e discutir tópicos que abordem a avaliação da qualidade de fenos e sua influência no desempenho animal. 
MOREIRA, K.K.G. et al. Avaliação da qualidade de feno. PUBVeT, Londrina, V. 7, N. 1, Ed. 224, Art. 1487, 2013.

\section{FATORES QUE AFETAM A QUALIDADE DO FENO}

O potencial da qualidade do feno é reflexo de inúmeros fatores, sendo os mais importantes àqueles que estão diretamente ligados com a escolha da forrageira, o processamento realizado a campo e com as condições de armazenamento.

O feno de boa qualidade é aquele que provém de uma forragem cortada no momento adequado, que passou por uma secagem bem feita, rápida e sem ocorrência de chuvas. É proveniente de solo bem adubado, isento de ervas daninhas, fungos e doenças. Feno de boa qualidade apresenta cor verde característica, maciez ao tato e excelente aroma (MICKENHAGEN, 1996).

REIS et al. (2001) citaram alguns fatores que podem afetar a qualidade do feno:

- O ambiente: fatores abióticos relacionados ao clima e bióticos relacionados ao pastejo, as pragas e as doenças, aplicação de fertilizantes e queimadas;

- Espécies forrageiras: as diversidades genéticas, as interações com o ambiente e o manejo fazem com que a expressão do valor nutritivo seja extremamente variável;

- Corte: com o crescimento da planta ocorrem alterações, que resultam na elevação dos teores de compostos estruturais, tais como a celulose, a hemicelulose e a lignina e, paralelamente, diminuição do conteúdo celular. $\mathrm{O}$ corte deve ser realizado quando a planta alcançar alto teor de proteínas, associado à elevada produtividade por hectare e baixo teor de fibra bruta;

- Armazenamento: fenos com alto conteúdo de água propiciam a continuação da respiração celular e o desenvolvimento de bactérias, fungos e leveduras. Assim, tem-se a utilização de carboidratos solúveis, compostos nitrogenados, vitaminas e minerais, o que leva a diminuição no conteúdo celular e aumento percentual na porção referente aos constituintes da parede celular, o que resulta em diminuição do valor nutricional.

Dentre os fatores que afetam a qualidade do feno, o tempo de desidratação é ponto primordial a ser controlado. A forragem permanecendo 
MOREIRA, K.K.G. et al. Avaliação da qualidade de feno. PUBVeT, Londrina, V. 7, N. 1, Ed. 224, Art. 1487, 2013.

cortada no campo para secagem pode sofrer alterações acentuadas em sua composição química e atividade fisiológica. É preciso que esse processo seja o mais rápido possível, para que as perdas de matéria seca e de nutrientes no produto final sejam menores.

A adoção de técnicas corretas de produção e manejo no plantio da forragem, processo de fenação, armazenamento e no fornecimento aos animais são necessárias para que as perdas sejam minimizadas (Tabela 1).

TABELA 1 - Previsão de perdas (\%) durante o processo de fenação em diferentes condições de secagem no campo

\begin{tabular}{lcccccc}
\hline \multirow{2}{*}{ Fontes de perdas } & \multicolumn{2}{c}{ Ótimas } & \multicolumn{2}{c}{ Normais } & \multicolumn{2}{c}{ Adversas } \\
\cline { 2 - 7 } & $\mathrm{P}$ & $\mathrm{C}$ & $\mathrm{P}$ & $\mathrm{C}$ & $\mathrm{P}$ & $\mathrm{C}$ \\
\hline Forragem cortada & - & 100 & - & 100 & - & 100 \\
Condicionamento & 5 & 95 & 10 & 90 & 20 & 80 \\
Respiração & 5 & 90 & 10 & 81 & 15 & 68 \\
Ancinho & 5 & 86 & 10 & 73 & 20 & 54 \\
Lixiviação & 0 & 86 & 10 & 66 & 15 & 46 \\
Enfardamento & 5 & 81 & 10 & 59 & 20 & 37 \\
Armazenamento & 5 & 77 & $10 / 20$ & $53-47$ & 30 & 26 \\
Manuseio & 5 & 74 & 10 & $48-43$ & 30 & 18 \\
Forragem & - & 74 & - & $48-43$ & - & 18 \\
Consumida & & & & & & \\
\hline P(\%) Perddo & & & & & &
\end{tabular}

$\mathrm{P}(\%)$ - Perdido $\mathrm{C}(\%)$ - Conservado.

Fonte: Adaptado de MACDONALD \& CLARK (1987) citado por REIS (2001)

Em fenos superaquecidos há formação de produtos de Maillard, que promovem a diminuição acentuada na digestibilidade da proteína, uma vez que se pode observar aumento considerável nos teores de nitrogênio insolúvel em detergente ácido (NIDA), o qual não é disponível para os microrganismos do rúmen. Portanto, o aumento de NIDA acarreta decréscimo de proteína solúvel 
MOREIRA, K.K.G. et al. Avaliação da qualidade de feno. PUBVeT, Londrina, V. 7, N. 1, Ed. 224, Art. 1487, 2013.

e elevação na quantidade de proteína bruta (PB) alterada pelo calor (REIS et al., 2001).

\section{CLASSIFICAÇÃO dO FENO}

SAMPAIO et al. (1997) proporão a avaliação química-bromatológica do feno, para que se conheça a composição do alimento e seja feito um balanceamento adequado da dieta. O teor de proteína bruta (PB) é um dos parâmetros utilizados para predizer a qualidade da forragem; o teor de matéria seca pode ser útil para predizer ou corrigir problemas de armazenamento; e o teor de fibra em detergente neutro (FDN) dá indicação do consumo de feno (TABELA 2).

Tabela 2- Interpretação da análise de fenos, segundo sugestão da EMBRAPA Gado de Leite

\begin{tabular}{lcc}
\hline \multirow{2}{*}{ Componentes } & \multicolumn{2}{c}{ Intervalos esperados em \% na MS } \\
\cline { 2 - 3 } & Gramínea & Leguminosa \\
\hline Umidade (\%) & $20-15$ & $18-15$ \\
Proteína bruta & $8-16$ & $15-24$ \\
Fibra em detergente neutro & $78-66$ & $54-38$ \\
Fibra em detergente ácido & $43-30$ & $44-28$ \\
Cinzas & $9-6,1$ & $10,2-8,9$ \\
Cálcio & $0,26-0,4$ & $1,25-2,3$ \\
Fósforo & $0,18-0,27$ & $0,20-0,35$ \\
Magnésio & $0,13-1,21$ & $0,30-0,50$ \\
Potássio & $1,3-1,2$ & $1,7-2,25$ \\
Lignina & $4-7$ & - \\
NDT (estimado \%) & $43-61$ & $54-76$ \\
\hline
\end{tabular}

Fonte: Adaptado de SAMPAIO et al. (1997) 
MOREIRA, K.K.G. et al. Avaliação da qualidade de feno. PUBVET, Londrina, V. 7, N. 1, Ed. 224, Art. 1487, 2013.

Denomina-se feno tipo A aquele produzido com forrageiras novas e com alto valor nutritivo, proporcionando material verde e isento de quaisquer tipos de contaminação, como fungos e materiais estranhos. O feno tipo B é produzido com forragem com o teor de matéria seca superior, no qual se consegue maior produtividade por área, porém, menor valor nutritivo e com um aspecto final mais amarelado. Já o tipo $C$ provém de forragem já passada ou de fenos $A$ e $B$ que foram expostos a chuvas, onde o valor nutritivo fica comprometido (SAMPAIO et al., 1997).

A EMBRAPA Gado de Leite adota a classificação de feno em três tipos $(A, B, C)$ em função do conteúdo de PB e FDN (Quadro 1).

QUADRO 1 - Classificação de fenos proposta pela EMBRAPA Gado de Leite

\begin{tabular}{|c|c|c|c|c|}
\hline Tipo & Forrageira & Teor de umidade & PB (\%MS) & FDN (\%MS) \\
\hline A & \multirow{3}{*}{ Gramínea } & $15-10$ & $>13$ & $<65$ \\
\cline { 4 - 5 } & & $18-15$ & $9-13$ & $65-69$ \\
\cline { 4 - 5 } B & $18-15$ & $<9$ & $>69$ \\
\hline C & & $18-15$ & $>20$ & $<41$ \\
\hline A & \multirow{2}{*}{ Leguminosa } & $18-15$ & $16-20$ & $41-46$ \\
\cline { 4 - 5 } B & & $18-15$ & $<16$ & $>46$ \\
\hline & & & \\
\hline
\end{tabular}

Fonte: Adaptado de SAMPAIO et al. (1997)

\section{AVALIAÇÃO DO CONSUMO DE FENO}

O consumo depende do volume estrutural e consequentemente do conteúdo de parede celular. É controlado pela quantidade de material degradável ou não degradável presentes no rúmen, e pode ser representado pela taxa de digestão e taxa de passagem da digesta através do retículo e do rúmen (VAN SOEST, 1994).

A regulação da ingestão envolve sinais de fome e saciedade que operam por intermédio de vários mecanismos hormonais e neurais para controlar a 
MOREIRA, K.K.G. et al. Avaliação da qualidade de feno. PUBVeT, Londrina, V. 7, N. 1, Ed. 224, Art. 1487, 2013.

ingestão voluntária. Quando dietas de alta qualidade são fornecidas, o animal se alimenta para satisfazer sua demanda de energia e a ingestão é limitada pelo potencial genético do animal em utilizar a energia absorvida. Entretanto, quando dietas de baixa qualidade são fornecidas, o animal consome o alimento ao nível que corresponde à capacidade do trato gastrintestinal (ÍTAVO et al., 2000).

O consumo de forragem pode ser influenciado por três fatores principais (SILVA, 2003):

- Os que afetam a ingestão da forragem, relacionados com a estrutura física do material forrageiro;

- Os que afetam a digestão da forragem, relacionados com a maturidade e concentração de nutrientes do material ingerido;

- E os que afetam a demanda por nutrientes e a capacidade digestiva do animal, que por sua vez, são reflexos da maturidade e estágio produtivo do animal.

O consumo de forragem e outros alimentos fibrosos podem ser aumentados substancialmente por moagem e peletização. A redução do tamanho de partícula e a ruptura da estrutura da parede celular aumentam a densidade do alimento. Ocorre também a redução do tempo de ruminação, com concomitante aumento do tempo disponível para alimentação. A maior densidade permite taxa de digestão mais rápida, e menor volume ruminal (PEREIRA et al., 2009).

Em experimento realizado com bovinos fistulados no rúmen e abomaso, recebendo dietas contendo feno de capim-tifton 85 , colhido aos $28,35,42$ e 56 dias de rebrota, adotando-se relação volumoso:concentrado de 60:40 (Tabela 3), RIBEIRO et al. (2001) estimaram o máximo consumo de matéria seca para rações contendo feno com 42 dias de idade. 
MOREIRA, K.K.G. et al. Avaliação da qualidade de feno. PUBVeT, Londrina, V. 7, N. 1, Ed. 224, Art. 1487, 2013.

TABELA 3 - Consumo médio de nutrientes em função das idades de rebrota do feno $(28,35,42$ e 56 dias) na ração

\begin{tabular}{lcccc}
\hline \multirow{2}{*}{ Item } & \multicolumn{4}{c}{ Idade do feno na ração (dias) } \\
\cline { 2 - 5 } & 28 & 35 & 42 & 56 \\
\hline MS & 5,39 & 5,85 & 5,72 & 5,27 \\
PB & 0,69 & 0,72 & 0,66 & 0,52 \\
EE & 0,13 & 0,15 & 0,14 & 0,11 \\
FDN & 3,09 & 3,38 & 3,37 & 3,06 \\
NDT & 3,98 & 4,18 & 4,11 & 3,51 \\
CHOSD & 3,85 & 4,04 & 3,98 & 3,4
\end{tabular}

Matéria seca (MS), matéria orgânica (MO), proteína bruta (PB), extrato etéreo (EE), fibra em detergente neutro (FDN), carboidratos totais (CHOS), nutrientes digestíveis totais (NDT), matéria orgânica digestível (MOD) e carboidratos totais digestíveis (CHOSD). Fonte: Adaptado de RIBEIRO et al., 2001.

Esses mesmos autores observaram comportamento quadrático dos consumos de matéria seca em função da idade do feno incluído nas dietas. Os autores atribuíram à redução no consumo de matéria seca, a partir de 42 dias de idade, ao mais alto teor de parede celular indigestível no feno.

SOUZA et al. (2010) avaliando o comportamento ingestivo de caprinos e ovinos alimentados com feno ou silagem de maniçoba, observaram que 0 consumo de PB e EE foram maiores nos animais que consumiram feno, pois o mesmo apresentou os teores mais elevados desses nutrientes em sua composição (Tabela 4). O consumo de FDN (CFDN) tanto para caprinos quanto por ovinos, foi considerado elevado, pelo fato dos altos teores de FDN na composição do feno e da silagem do material do estudo, o que resultou em menor ingestão de matéria seca (MS) devido ao limite físico do rúmen-retículo. 
MOREIRA, K.K.G. et al. Avaliação da qualidade de feno. PUBVeT, Londrina, V. 7, N. 1, Ed. 224, Art. 1487, 2013.

TABELA 4 - Média de consumo de nutrientes do feno e da silagem de maniçoba em caprinos e ovinos

\begin{tabular}{|c|c|c|c|c|c|c|c|c|}
\hline \multirow{2}{*}{ Item } & \multicolumn{2}{|c|}{ Conservação(C) } & \multicolumn{2}{|c|}{ Espécie(E) } & \multicolumn{3}{|c|}{ Efeito } & \multirow{2}{*}{$\begin{array}{l}\mathrm{CV}^{1} \\
(\%)\end{array}$} \\
\hline & Silagem & Feno & Caprino & Ovino & $\mathrm{C}$ & $E$ & $\mathrm{CxE}^{2}$ & \\
\hline CMS (kg/dia) & 0,453 & 0,457 & 0,446 & 0,464 & ns & ns & ns & 14,1 \\
\hline CMS (\%PV) & 3,18 & 2,97 & 3,01 & 3,16 & ns & ns & ns & 13,1 \\
\hline $\mathrm{CMS}\left(\mathrm{kg} / \mathrm{PV}^{0,75}\right)$ & 63,53 & 58,23 & 60,11 & 61,88 & ns & ns & ns & 12,7 \\
\hline CMO (kg) & 0,41 & 0,39 & 0,40 & 0,41 & ns & ns & ns & 16,4 \\
\hline $\mathrm{CMO}(\% \mathrm{PV})$ & 2,90 & 2,69 & 2,80 & 2,88 & ns & ns & ns & 15,7 \\
\hline CPB (kg) & $0,042 b$ & $0,056 a$ & 0,048 & 0,049 & $*$ & ns & ns & 13,5 \\
\hline CFDN (kg) & 0,26 & 0,23 & 0,24 & 0,25 & ns & ns & ns & 16,3 \\
\hline CFDN(\%PV) & 1,82 & 1,60 & 1,67 & 1,76 & ns & ns & ns & 14,1 \\
\hline CEE $(\mathrm{kg})$ & $0,014 b$ & $0,024 a$ & 0,019 & 0,019 & $*$ & ns & ns & 15,3 \\
\hline $\mathrm{CCHT}(\mathrm{kg})$ & 0,36 & 0,31 & 0,33 & 0,34 & ns & ns & ns & 16,9 \\
\hline CCNF (kg) & 0,098 & 0,085 & 0,091 & 0,092 & ns & ns & ns & 20,7 \\
\hline
\end{tabular}

Médias seguidas de letras distintas nas linhas diferem estatisticamente pelo teste de Tukey (5\%). Consumo de matéria seca (CMS), matéria orgânica $(\mathrm{CMO})$, proteína bruta $(\mathrm{CPB})$, extrato etéreo $(\mathrm{CEE})$, carboidratos totais (CCHT), carboidratos não fibrosos (CCNF) e fibra em detergente neutro (CFDN). Fonte: Adaptado de SOUZA et al. (2010).

FERNANDES et al. (2002) avaliando a qualidade de feno de Brachiaria decumbens amonizado, fornecido a novilhos zebu, observaram que houve incremento nos valores de consumo de MS em relação ao peso dos animais (CMS/PV). Os animais alimentados com feno não tratado apresentaram consumo de $1,97 \% \mathrm{PV}$, nos que recebiam feno tratado com $\mathrm{NH}_{3}$ o consumo foi de $2,23 \%$ do PV e na dieta com feno tratado com uréia foi de 1,90\% PV, evidenciando superioridade do feno tratado com $\mathrm{NH}_{3}$. 
MOREIRA, K.K.G. et al. Avaliação da qualidade de feno. PUBVeT, Londrina, V. 7, N. 1, Ed. 224, Art. 1487, 2013.

\section{AVALIAÇÃO DA DIGESTIBILIDADE DO FENO}

Muitas pesquisas sobre feno são voltadas para área agronômica e levam apenas em consideração a produtividade e a composição bromatológica. Outras formas de avaliação da qualidade dos fenos são os ensaios de digestibilidade ruminal (LADEIRA et al., 2001).

As características de degradação das forragens, particularmente a taxa de degradação ruminal, fornecem uma estimativa da digestibilidade, a qual exerce extensa influência sobre o consumo (SILVA, 2003). A digestibilidade depende do conteúdo de parede celular e da disponibilidade desta para digestão, em função da lignificação e de outros fatores (VAN SOEST, 1994).

A parede celular é o maior constituinte da matéria seca das forrageiras. Sua degradação ruminal é mais lenta e variável, sendo assim, componente limitante na utilização da forragem pelo animal. A digestibilidade da parede celular pode ser influenciada por fatores externos, como a presença de ceras e cutina, que limitam o acesso das bactérias ao interior dos tecidos da planta, impedindo assim que sejam fragmentados e degradados, ou a fatores internos, como a lignina que tem sido constantemente associado à fração indigestível da parede celular em forrageiras (REFFATTI, 2006).

A digestibilidade pode ser estimada por meio da digestibilidade aparente, digestibilidade in vivo e por meio de simulação das condições de fermentação ruminal utilizando métodos in vitro e in situ.

Em experimento realizado com carneiros recebendo feno de capim Brachiaria decumbens cortado em três idades de crescimento (Tabela 5), RAMIREZ et al. (2010) constataram que os valores de digestibilidade aparente da matéria seca dos fenos do capim cortado aos 56 e 84 dias foram superiores ao do capim cortado aos 112 dias, demonstrando que a idade da planta pode interferir na digestibilidade do feno. Resultados semelhantes foram encontrados em experimento de RIBEIRO et al. (2001), no qual os autores constataram que a ração contendo feno de capim-tifton 85 de 56 dias de idade apresentou tendência de baixos coeficientes de digestibilidade dos nutrientes, 
MOREIRA, K.K.G. et al. Avaliação da qualidade de feno. PUBVeT, Londrina, V. 7, N. 1, Ed. 224, Art. 1487, 2013.

o que pode ser atribuído ao mais baixo teor proteico e de nutrientes digestíveis totais, além do mais alto teor de FDN indigestível do feno incluído nessa ração.

TABELA 5 - Consumo voluntário de feno de Brachiaria decumbens cortado aos $56,84,112$ dias de crescimento.

\begin{tabular}{ccccc}
\hline Idade ao corte & CMO & CMST & CMSUTM & DAMS \\
\hline 56 & 882,4 & 948,13 & 65,6 & $55,96 \mathrm{~A}$ \\
84 & 846,7 & 905,13 & 60,37 & $53,68 \mathrm{~A}$ \\
112 & 787,5 & 841,2 & 57,66 & $45,61 \mathrm{~B}$ \\
CV(\%) & 17,34 & 17,31 & 8,51 & 10,78 \\
\hline
\end{tabular}

Letras maiúsculas nas colunas representam diferença estatística $(P<0,05$; SNK); Matéria orgânica (CMO, g/dia), consumo de matéria seca total (CMST, $\mathrm{g} /$ dia), consumo de matéria seca por unidade de tamanho metabólico (CMSUTM, g/UTM/dia) e digestibilidade aparente da matéria seca (DAMS, \%).

Fonte: Adaptado de RAMIREZ et al. (2010)

Trabalhando com diferentes fontes de fibra (feno de capim-tifton, caroço de algodão e casca de soja) na inclusão em dietas à base de palma forrageira para ovinos em terminação, COSTA (2009) verificou que o feno de capim-tifton propicia um maior tempo de ruminação e apresenta coeficientes de digestibilidade da matéria seca e da matéria orgânica intermediários (TABELA 6), sendo recomendado, juntamente com a casca de soja, como uma possível fonte de fibra.

A oferta adicional de substratos a microbiota ruminal pode aumentar seu crescimento e sua atividade, possibilitando assim, o aumento da degradação das forragens no rúmen. A suplementação de bovinos consumindo forrageiras de baixa qualidade (baixo teor de proteína e alto teor de fibra) com proteína degradável no rúmen, frequentemente resulta no aumento do consumo e digestão do alimento (REFFATTI, 2006). 
MOREIRA, K.K.G. et al. Avaliação da qualidade de feno. PUBVeT, Londrina, V. 7, N. 1, Ed. 224, Art. 1487, 2013.

TABELA 6 - Digestibilidade aparente dos nutrientes em função das diferentes fontes de fibra

\begin{tabular}{lcccc}
\hline \multirow{2}{*}{ Item (\%) } & \multicolumn{3}{c}{ Fontes de fibra } \\
\cline { 2 - 4 } & FCT & CS & CA & CV (\%) \\
\hline Matéria seca & $76,03 \mathrm{~b}$ & $83,23 \mathrm{a}$ & $71,89 \mathrm{~b}$ & 7,98 \\
Matéria orgânica & $78,76 \mathrm{~b}$ & $86,72 \mathrm{a}$ & $75,42 \mathrm{~b}$ & 7,85 \\
Proteína bruta & $77,56 \mathrm{a}$ & $81,16 \mathrm{a}$ & $68,95 \mathrm{~b}$ & 7,62 \\
Extrato etéreo & $58,46 \mathrm{~b}$ & $61,46 \mathrm{~b}$ & $85,94 \mathrm{a}$ & 23,6 \\
Fibra em detergente neutro & $68,28 \mathrm{a}$ & $74,15 \mathrm{a}$ & $64,55 \mathrm{a}$ & 11,35 \\
\hline
\end{tabular}

Médias na linha seguidas de letras distintas diferem estatisticamente pelo teste de SNK $(P<0,10)$. FCT- Feno de capim-tifiton, CS - Casca de soja e CA Caroço de algodão.

Fonte: Adaptado de COSTA (2009)

REIS et al. (2001) observaram que houve significativo aumento na digestibilidade in vitro da matéria seca dos fenos de Brachiaria brizantha, quando estes foram tratados com amônia $(20,4 \%)$ e com uréia $(14,6 \%)$. Os autores atribuíram essa variação de incrementos na digestibilidade a diminuição nos teores de fibra em detergente neutro e hemicelulose, ou seja, à solubilização que acarretou no aumento do conteúdo de carboidratos prontamente digestíveis e de nitrogênio disponível para os microrganismos do rúmen, o que também pôde ser confirmado por PIRES et al. (2003) em revisão sobre amonização.

\section{AVALIAÇÃO DO DESEMPENHO ANIMAL}

A ingestão de matéria seca é um dos fatores determinantes do desempenho animal, sendo o ponto inicial para o ingresso de nutrientes, principalmente de energia e proteína, necessários para o atendimento das exigências de mantença e produção (NOLLER et al., 1997). O atendimento das exigências de mantença e produção é determinante para alcançar o 
MOREIRA, K.K.G. et al. Avaliação da qualidade de feno. PUBVeT, Londrina, V. 7, N. 1, Ed. 224, Art. 1487, 2013.

desempenho animal desejado.

Com o objetivo de avaliar o desempenho e as características de carcaça de 12 animais $1 / 2$ Nelore $1 / 2$ Aberdeen Angus, alimentados com fenos de resíduo de pós-colheita de sementes de Brachiaria brizantha, tratados quimicamente com amônia anidra, ureia ou com fonte proteica suplementar ao feno não tratado, ROTH (2008) verificou que embora todos os tratamentos alimentares proporcionaram aos animais pesos adequados para abate comercial, os valores de peso vivo final (PVF) apresentaram diferença significativa, sendo os animais alimentados com feno tratado com 3\% de amônia na MS apresentaram maior PVF (Tabela 7). A utilização de amônia no tratamento do feno de resíduo de pós-colheita de sementes mostrou-se como alternativa eficiente na alimentação de bovinos confinados e proporcionou a produção de carcaças com acabamento desejável ao processo produtivo de carnes.

TABELA 7- Média de desempenho dos animais alimentados com dietas de feno não tratado com suplementação de nitrogênio não proteico (FNTNNP), feno não tratado com suplementação de farelo de algodão (FNTFA), feno tratado com ureia (FTU) e feno tratado com amônia anidra (FTA)

\begin{tabular}{lccccccc}
\hline Parâmetros & FNTNNP & FNTFA & FTU & FTA & MEDIAS & CV1 & P>F \\
\hline PVI & 414,3 & 416,7 & 431,0 & 428,5 & 422,6 & 6,22 & 0,62 \\
PVF & $484,8 \mathrm{~b}$ & $510,7 \mathrm{ab}$ & $513,7 \mathrm{ab}$ & $539,2 \mathrm{a}$ & 512,0 & 5,33 & $*$ \\
GMD & $0,871 \mathrm{~b}$ & $1,161 \mathrm{ab}$ & $1,014 \mathrm{~b}$ & $1,336 \mathrm{a}$ & 1,103 & 17,99 & $* *$ \\
CA & $10,91 \mathrm{a}$ & $8,98 \mathrm{ab}$ & $9,83 \mathrm{ab}$ & $7,78 \mathrm{~b}$ & 9,37 & 16,64 & $* *$ \\
\hline
\end{tabular}

Médias seguidas de letras distintas nas linhas diferem estatisticamente pelo teste de Tukey (5\%).

Fonte: Adaptado de ROTH (2008)

Estudando o desempenho animal em função das diferentes fontes de fibra (feno de capim-tifton, casca de soja e caroço de algodão) em dietas à 
MOREIRA, K.K.G. et al. Avaliação da qualidade de feno. PUBVET, Londrina, V. 7, N. 1, Ed. 224, Art. 1487, 2013.

base de palma forrageira para ovinos em terminação, COSTA (2009) observou que o ganho de peso médio diário (GPD) dos animais alimentados com a dieta de feno de capim-tifton foi superior aos dos animais alimentados com caroço de algodão, porém foi menor do que o GPD dos animais alimentados com casca de soja (Tabela 8).

TABELA 8 - Desempenho animal em função das diferentes fontes de fibras nas dietas

\begin{tabular}{lcccc}
\hline \multirow{2}{*}{ Itens } & \multicolumn{3}{c}{ Fontes de fibra } & \\
\cline { 2 - 4 } & FCT & CS & CA & CV (\%) \\
\hline Peso inicial kg & 18,7 & 19,64 & 18,37 & - \\
Peso final kg & 31,24 & 31,76 & 31,11 & - \\
Ganho de peso diário (kg/dia) & $0,15 \mathrm{a}$ & $0,14 \mathrm{a}$ & $0,11 \mathrm{~b}$ & 24,4 \\
Conversão alimentar (kgMS/kg de GDP) & $7,88 \mathrm{~b}$ & $8,87 \mathrm{~b}$ & $9,51 \mathrm{a}$ & 26,47 \\
Confinamento (dias) & 83 & 86 & 115 & \\
\hline Médias seguidas de letras distintas nas & linhas diferem estatisticamente pelo \\
teste de Tukey (5\%). FCT- Feno de capim-tifiton, CS - Casca de soja e CA - \\
Caroço de algodão. \\
Fonte: Adaptado de coSTA (2009)
\end{tabular}

Os animais que receberam a dieta de feno de capim-tifton apresentaram menor tempo de permanência no confinamento, o que indica uma redução na idade de abate e menores custos de produção.

\section{CONSIDERAÇÕES FINAIS}

A produção, secagem e o armazenamento adequado de forragens, é atividade de suma importância nos sistemas de produção de fenos. Nestas condições, a fenação é uma garantia do fornecimento de forragem de alta qualidade durante todo o ano para os animais, além de ser uma técnica de extrema eficiência para o manejo adequado das pastagens. 
MOREIRA, K.K.G. et al. Avaliação da qualidade de feno. PUBVET, Londrina, V. 7, N. 1, Ed. 224, Art. 1487, 2013.

A escolha das espécies forrageiras adaptadas ás condições climática e de solo, a adoção de manejo compatível com as características morfofisiológicas devem ser observadas para se garantir a qualidade e a produtividade da forragem.

O feno de boa qualidade é aquele que proporciona respostas satisfatórias no desempenho animal, apresentando um consumo adequado pelos animais e consequentemente uma alta digestibilidade.

\section{REFERÊNCIAS}

COSTA, S. B. M. Feno de capim-tifton, casca de soja, caroço de algodão como fonte de fibra em dietas à base de palma forrageira para ovinos. 2009, 44f. Dissertação (Mestrado em Zootecnia) - Universidade Federal Rural de Pernanbuco, Recife, 2009.

FERNANDES, L. O.; REIS, R. A.; RODRIGUES, L. R. A.; LEDIC, I.L.; MANZAN, R. J. Qualidade de feno de Brachiaria decumbens Stapf. submetido ao tratamento com amônia anidra ou uréia. Revista Brasileira de Zootecnia, v.31, n.3, p.13251332, 2002 (suplemento).

ÍTAVO, L. C. V.; SANTOS, G. T.; JOBiM, C. C.; VOlTOlini, T. V.; FERREIRA, C. C. B. Substituição da Silagem de Milho pela Silagem do Bagaço de Laranja na Alimentação de Vacas Leiteiras. Consumo, Produção e Qualidade do Leite. Revista Brasileira de Zootecnia, Viçosa, v.29 n.5, 2000.

JOBIM, C. C.; LOMBARDI, L.; GONÇALVES, G. D.; CECATO, U.; SANTOS, G. T.; CANTO, M. W. Desidratação de cultivares de Cynodon spp. durante o processo de fenação. Acta Scientiarum Animal Sciences, Maringá, v. 23, n. 4, p. 795-799, 2001.

JOBIM, C. C.; NUSSIO, L. G.; REIS, R. A.; SCHMIDT, P. Avanços metodológicos na avaliação da qualidade da forragem conservada. Revista Brasileira de Zootecnia, Viçosa, v.36, suplemento especial, p.101-119, 2007.

LADEIRA, M.M.; RODRIGUEZ, N.M.; GONÇALVES, L.C.; BORGES, I.; BENEDETTI, BRITO, S.C.E.; SÁ, L.A.P. Cinética ruminal do feno deStylosanthes guianensis. Arquivo Brasileiro de Medicina Veterinária e Zootecnia, Belo Horizonte, v. 53, n. 2, 2001.

MALLMANN, G. M.; PATINO, H. O.; SILVEIRA, A. L. F.; MEDEIROS, F. S.; KNORR, M. Consumo e digestibilidade de feno de baixa qualidade suplementado com nitrogênio não protéico em bovinos. Pesquisa Agropecuária Brasileira, Brasília, v.41, n.2, p.331-337, fev. 2006

MICKENHAGEN, R. Produção de Feno ao Nível do Produtor. Workshop sobre o potencial forrageiro do gênero Cynodon, 1996, Juiz de Fora. Anais...Juiz de Fora : EMBRAPA-CNPGL, p. 69-75.

NOLLER, C.H.; NASCIMENTO JR.D.; QUEIROZ, D.S. Determinando as exigências nutricionais de animais em pastejo.In: SIMPÓSIO SOBRE MANEJO DE PASTAGENS, 13., 1996, Piracicaba. Anais... Piracicaba, SP: FEALQ,1997. 
PÁDUA, F.T.; ALMEIDA, J.C.C.; NEPOMUCENO, D.D.; CABRAL NETO, O.; DEMINICIS, B.B. Efeito da dose de uréia e período de tratamento sobre a composição do feno de Paspalum notatum. Archivo Zootecnia, Cordoba, v. 60, n.229, p.57-62, 2011.

PEReirA, E. S.; MIZUBUTI, I. Y.; RIBEIRO, E. L. A.; VILLARROEL, A. B. S. PIMENTAL, P. G. Consumo, digestibilidade aparente dos nutrientes e comportamento ingestivo de bovinos da raça Holandesa alimentados com dietas contendo feno de capim-tifton 85 com diversos tamanhos de partícula. Revista Brasileira de Zootecnia, Viçosa, v.38, n.1, p.190-195, 2009.

PIRES, A.J.V.; REIS, R.A.; SIQUEIRA, G.R.; BERNARDES, T.F.; BERTIPAGIA, L.M.A.; RESENDE, K.T.; BERCHIELLI, T.T.; RUGGIERI, A.C.; CARVALHO, G.G.P. Composição química do feno de Brachiaria brizantha amonizado em diferentes umidades. Archivos de Zootecnia, Cordoba, $v$ 55, n. 212, p. 393-396, 2003.

RAMIREZ, M. A. Consumo e digestibilidade aparente de fenos de Brachiaria decumbens, stapf cultivar basiliski cortados em tres diferentes idades. 2010, $48 \mathrm{f}$. Dissertação (Mestrado em Zootecnia). Escola de Veterinária da Universidade Federal de Minas Gerais, Belo Horizonte, 2010.

REFFATTI, M. V. Valor alimentar do feno de tifton 85 (cynodon sp.) com ou sem suplementação com ureia, caseína ou farinha de mandioca. 2006, 56 f. Dissertação (Mestrado em Zootecnia) - Universidade Federal de Santa Maria, Santa Maria, 2006.

REIS, R. A.; MOREIRA, A. L.; PEDREIRA, M. S. Técnicas para produção e conservação de fenos de alta qualidade. Simpósio sobre Produção e Utilização de Forragens Conservadas: 01 ed., Maringá, Universidade Estadual de Maringá. p. 1-39, 2001.

RIBEIRO, K. G.; GARCIA, R.; PEREIRA, O. G.; VALADARES FILHO, S. C.; CECON, P. R. Consumo e Digestibilidades aparentes total e parcial, de nutrientes, em bovinos recebendo rações contendo feno de capim-tifton 85 de diferentes idades de rebrota. Revista Brasileira de Zootecnia, Viçosa, v. 30, n. 2, p. 573-580, 2001.

ROTH, M. T. P. Avaliação da amonização de fenos de resíduo de pós-colheita de sementes de Brachiaria brizantha cv. Marandu. 2008. 78f. Dissertação (Mestrado em Zootecnia) - Faculdade de Ciências Agrárias e Veterinárias da Universidade Estadual Paulista, Jaboticabal, 2008.

SAMPAIO, A.O., OLIVEIRA, J.S., COSTA, J.L., RESENDE, H. Conservação de forrageiras e pastagens. In: EMBRAPA - Centro Nacional de Pesquisa de Gado de Leite (Org.) Trabalhador na bovinocultura de leite: manual técnico, 1997. Belo Horizonte: SENARAR/MG / EMBRAPA, p.67-100.

SILVA, B. ; PEREIRA, O. G.; PEREIRA, D. H. Consumo e digestibilidade aparente total dos nutrientes e ganho de peso de bovinos de corte alimentados com silagem de Brachiaria brizantha e concentrado em diferentes proporções. Revista Brasileira de Zootecnia, Viçosa, v. 34, n. 3, p. 1060-1069, 2005.

SILVA, R. L. N. V. Composição química, consumo e digestibilidade aparente de dietas contendo diferentes níveis de farelo de melancia forrageira (Citrullus lanatus cv. citroides) e feno de guandu (Cajanus cajan cv. D Type), em ovinos. 2003. 57f. Dissertação (Mestrado em Medicina Veterinária Tropical) - Escola de Medicina Veterinária da Universidade Federal da Bahia, Salvador, 2003. 
SILVEIRA, A.C. et al. Sistema de produção de novilhos superprecoce. In.: Simpósio goiano sob produção de bovinos de corte, 1999, Goiânia. Anais... Goiânia: CBNA, 1999. p.105-122.

SOUZA, E. J. O.; GUIM, A.; BATISTA, A M. V.; ALBUQUERQUE, D. B.; MONTEIRO, C. C. F.; ZUMBA, E. R. F.; TORRES, T. R. Comportamento ingestivo e ingestão de água em caprinos e ovinos alimentados com feno e silagem de Maniçoba. Revista Brasileira de Saúde e Produção Animal, Salvador, v.11, n.4, p.1056-1067, 2010.

VAN SOEST, P.J. Nutritional ecology of the ruminant. 2nd ed. New York: Cornell University Press, 1994. 476p. 